\title{
Makaleler
}

\section{Türkiye'de Dolaylı Vergilerin Enflasyon Üzerindeki Etkisi}

Adil AKINCl' - ÖZer ÖZÇELIK²

Makale Gönderim Tarihi : 28.08.2018

Makale Kabul Tarihi : 24.09.2018

\section{Öz}

Vergilerin mali olan ve mali olmayan amaçları bulunmaktadır. Vergilerin mali olan amaçlarını temelde kamu harcamalarının finansmanını sağlayacak gelirin elde edilmesi oluștururken, vergilerin mali olmayan amaçlarını ise ekonomik istikrar, ekonomik büyüme ve gelișme ile adil gelir dağılımı hedefleri olușturmaktadır. Mali olmayan amaçlardan ekonomik istikrar ele alındığında fiyat istikrarı ve tam istihdam düzeyi söz konusu olmaktadır. Fiyat istikrarı denilince gelișmekte olan ülkelerde genellikle enflasyon ön plana çıkmaktadır. Bu kapsamda çalıșmada, Türkiye'de 2006:M1-2018:M5 döneminde dolaylı vergiler ile enflasyon arasındaki ilișki zaman serisi analizi yöntemlerinden ARDL (Otoregresif Dağıtılmıș Gecikme Modeli) ile incelenerek, vergilerin mali olmayan amaçları konusundaki etkinliği araștırılmıștır. Elde edilen bulgular neticesinde, dolaylı vergiler ile enflasyon arasında uzun dönemli bir eșbütünleșme ilișkisinin olduğu tespit edilmiștir.

Anahtar Kelimeler: Dolaylı Vergi, Enflasyon, Zaman Serisi Analizi, ARDL

JEL Kodları: A10, C50, E69

1 Dr.Öğr.Üyesi Adil AKINCl- Kırklareli Üniversitesi Uygulamalı Bilimler Yüksekokulu Bankacılık ve Finans Bölümü- adil.akinci@klu.edu.tr, Orcid No: 0000-0002-2181-6952

2 Dr.Öğr.Üyesi Özer ÖzÇELIKK-Dumlupınar Üniversitesi İktisadi İdari Bilimler Fakültesi İktisat Bölümü- ozer.ozcelik@dpu.edu.tr, Orcid No: 0000-0001-9164-5020 


\section{Effect of Indirect Taxes on the Inflation in Turkey}

\section{Abstract}

Taxes have financial and non-financial objectives. While revenue generation to ensure the financing of public expenditures basically constitutes the financial objectives of taxes, economic stability, economic growth and development and fair income distribution targets constitute the non-financial objectives of taxes. When economic stability, one of non-financial objectives, is considered, price stability and full employment level come into question. When it comes to price stability, inflation usually comes to the forefront in developing countries. In this context, in the study, the relationship between indirect taxes and inflation during 2006:M1-2018:M5 period in Turkey was analyzed by the ARDL (Autoregressive Distributed Lag Model), which is one of time series analysis methods, and its effectiveness on non-financial objectives of taxes was investigated. As a result of the findings obtained, it has been determined that there is a long-term cointegration relationship between indirect taxes and inflation.

Keywords: Indirect Tax, Inflation, Time Series Analysis, ARDL

JEL Codes: A 10, C50, E69

\section{Giriș}

İktisadi dengesizliklerin enflasyon oranının yüksek olması sonucu ortaya çıktığı ekonomilerde, devletin kamu harcamalarına yönelik program hazırlaması zorlașmaktadır. Enflasyondaki konjonktürel dalgalanmaların sebebi olarak vergi oranlarındaki artıșlar gösterilmektedir. Enflasyonist bir ortamda, vergi gelirlerinin reel değerinde azalmalar ortaya çıkacaktır. Türkiye'de dolaylı vergilerin toplam vergi gelirleri içerisindeki payının dolaysız vergi gelirlerinden daha yüksek olması nedeniyle, hem kaynak dağılımında hem de gelir dağılımında adaletsizlik göze çarpmaktadır. Türkiye'de dolaylı vergi artıșları, fiyat artıșı olarak algılanmakta ve böylece tüketicilerin marjinal tüketim eğilimleri 1'e yakın olduğu görülmektedir. Bir bașka ifade ile, tüketiciler gelirlerinin büyük bir kısmını tüketerek ancak minimum yașam standartlarını yakalayabilmektedir. Böylece tüketicilerin tasarruf eğilimleri düșük seviyelerde kalmakta olup, bundan dolayı enflasyonla mücadelede dolaylı vergiler bir araç olarak kullanılmaktadır. Bu çalıșmada, Türkiye'de 2006:M1-2018:M5 döneminde dolaylı vergiler ile enflasyon arasındaki ilișki zaman serisi analizi yöntemlerinden ARDL ile analiz edilerek, elde edilen bulgular değerlendirilmiștir. 


\section{Dolaylı Vergilerin ve Enflasyonun Teorik Çerçevesi}

Vergi, kamu hizmetlerinin finanse edilmesi için devlet tarafından kiși ve kurumlardan alınan yasama yetkisine bağlı cebren aldıkları ayni veya nakdi ödeneklerdir (Șen ve Sağbaș, 2015:2). Vergi kelimesi, tahmini anlamına gelen Latince taxare kelimesinden türemiștir. Vergi, gönüllü bir ödeme veya bağıș değildir, ancak yasama organı uyarınca uygulanan zorunlu bir katkıdır. Vergilendirmenin bilinen ilk sistemi Eski Mısır'da M.Ö. 3000 - M.Ö. 2800 yıllarında hazırlanmıșır. O zamanlardaki kayıtlar firavun krallı̆ı̆ı iki yılda bir halktan vergi gelirleri toplayacağını göstermektedir. Daha sonra bulunan kayıtlar ise, kireçtașı gevreği ve papirüs üzerine yazılan tahıl ambarı makbuzlarıdır (Garg, 2014:542-543). Eski Roma'da Tributum denilen vergi savașlarda kaybeden devletin kazanan devlete ödediği bedel anlamına gelmektedir. Ortaçağ Avrupa'sında vergi yerine kullanılan kelimeler hediye, yardım, fedakârlık kökünden gelen kelimelerdir. Bu çağda verginin niteliğinde cebir unsuru yoktur. İslam coğrafyasında ise, nakdi sermayenin atıl tutulması hos görülmemiș bunlardan vergi (zekat) alınarak yatırım ve harcamaya dönüștürülmesi teșvik edilmiștir (Mutlu, 2009:19-20). Osmanlı Devletinde vergi kelimesi yerine resim, tekalif, bac ve adet kelimeleri kullanılmıștır. İslami esaslara dayanan (Tekalif-i Șeriyye) ve dini esaslara dayanmayan (Tekalif-i Örfiyye) vergiler olarak iki çeșit vergi alınmıșır (Özçelik, 2015:67-68).

Vergiler, dolaysı/dolaylı olmalarına göre, konularına göre veya kișisel ve objektif olmalarına göre ayırıma tabi tutulabilirler. Vergilerin, vergilemede adalet ilkesine uyup uymadığını gösteren en önemli ayırım, dolaysız/dolaylı vergi ayırımıdır. Vergilerin dolaysız ve dolaylı ayırımında kullanılan en önemli kriterler verginin yansıması, vergi konusunun sürekliliği ve mükellefinin önceden belli olmasıdır (Çelik, 2016:256-257).

Tahsil süresi mutlak, konusu ve mükellefiyeti sürekli, kiși ve kurumların ödeme güçlerinin kavranmasını hedef alan ve yansııılması kolay olmayan vergiler; dolaysız vergi olarak sıniflandırılmaktadır (Cural ve Çevik, 2015:131).

Dolaylı vergiler, vergi mükellefinin durumunu dikkate almadan üretim, tüketim, değișim gibi ekonominin ana bölümlerine dayalı olarak alınır. Gelir ve servet kazanıldığı zamanda değil, harcandıkları an mal ve hizmetlerin fiyatları içine gizlenmiș olarak vergilendirirler. Bundan dolayı vergilendirilmiș malları çok kullananlar diğerlerine göre daha fazla vergi öderler (Erginay, 1976:121). Harcamalar üzerinden alındığı için gelir da- 
ğılımını bozan bir vergi türü olarak nitelemek mümkündür. Kolay toplanması ve mali anestezi yoluyla hissettirilmeyen bir vergi türü olması nedeniyle politika yapıcılar tarafından çok fazla tercih edilen bir vergi türüdür.

Enflasyon ise; bir ekonomideki mal ve hizmetlerin fiyatlarında gözlenen sürekli ve genel kapsamlı artıșı ifade etmektedir. Enflasyon, tüm mal ve hizmetlerde meydana gelen fiyat değișikliğini içermektedir. Diğer bir anlatıșla; bir ülkede, enflasyon oranı yükselirken bazı mal ve hizmetlerin fiyatları düșebilmekte veya aynı șekilde enflasyon oranı düșerken bazı mal ve hizmetlerin fiyatlarında yükselme yașanabilmektedir. Aynı zamanda fiyatlarda yașanan artıșın enflasyon olarak tanımlanabilmesi için sadece belirli bir dönem için değil, sürekli olması gerekmektedir (TCMB, 2013:2).

Genel olarak, gelișmiș ülkelerde enflasyonun nedeni olarak para arzının büyümesi gösterilmektedir. Gelișmekte olan ülkelerde ise, enflasyon, salt parasal bir olgu değildir. Bunun yanı sıra, ödemeler dengesi krizinden kaynaklanan hızlı para büyümesi ve döviz kurundaki oynaklık gibi mali dengesizlikler ile tipik olarak ilișkili faktörler, gelișmekte olan ülkelerdeki enflasyon sürecine hâkim olmaktadır (Totonchi, 201 1:459).

\section{Dolaylı Vergiler ile Enflasyon Arasındaki ilișiki}

Enflasyon ile vergi gelirleri arasında yapılmıș olan çalıșmalar, Petrol Krizi ile birlikte literatürde yer almaya bașlamıș ve genel olarak da enflasyonun vergi gelirlerini ne ölçüde etkilediği incelenmiștir. Enflasyonun vergi gelirlerini olumlu mu olumsuz mu etkilediğini belirlemek, ekonomik yapının analiz edilmesi için önem tașımaktadır. Bundan dolayı bir ülkede, enflasyonun vergi gelirlerinin reel değerini arttırması için üç temel șartın gerçekleșmesi gerekmektedir (Șen, 2003: 31 )

- Vergiye tabi kazançlar, enflasyon oranındaki yükselișe paralel olarak artmalıdır,

- Artan oranlı vergi tarifesi uygulanmalıdır,

- Vergiyi doğuran olay ile vergi tahsilatı arasındaki süre kısa olmalıdır.

Enflasyonist bir ekonomide, vergi gelirlerini arttırabilmek için, kısa dönemde bütçe fazlası olușturarak parasal likiditenin azaltılması gerekmekte olup, bu durum ise satın alma gücünü olumsuz etkilemektedir. Vergi oranlarındaki artıș, toplam arz ve toplam talep üzerinde etkili olmaktadır. Toplam talep açısından bakıldığında, vergilerin anti-enflasyonist 
bir yapıda olduğu görülmektedir. Toplam arz açısından ise, vergileme enflasyonist etkiler ortaya çıkarabilir. Dolaylı vergiler, malların fiyatları üzerinde etki yaratmakta ve böylece enflasyonist bir olguya sebep olmaktadır. dolaylı vergi artıșları, toplam tüketim harcamalarının düșürülmesi sonucu, refah kaybına sebep olmakta ve tüketici artığını azaltmaktadır. Toplam tasarruf açısından ise, tüketimden tasarrufa doğru bireysel tercihlerin değiștiği görülmektedir. Toplam talep temelli enflasyonun ve makroekonomik dengesizliklerin ortaya çıktığı iktisadi yapılarda, dolaylı vergi artıșları ekonomideki fazla talebi düșürmekte ve iktisadi denge sağlanmaya çalıșılmaktadır. Ayrıca, dolaylı vergi artıșlarıyla ihraç edilebilir mal fazlası yurtiçi talebin kısılması sonucunda ortaya çıkmaktadır. Böylece ekonomik küçülme olmadan ekonomik istikrar büyüme ile eșanlı olarak gerçekleștirilebilmektedir. Klasik IMF istikrar politikası önlemlerinde, dolaylı vergi artıșı enflasyonla mücadele için önemli bir araç olarak kullanılmaktadır (Mutlu ve Çelen, 2012:19-21).

\section{Literatür}

Karadağ ve Westaway (1999) Türkiye için yapmıș oldukları çalıșmalarında, Türkiye ekonomisinin Avrupa Birliği uyum sürecinde Hesaplanabilir Genel Denge Modelini geliștirmișlerdir. Modele göre, Katma Değer Vergisi oranındaki değișimlerin, tüm sektörlerde tüketici fiyatlarında bir artıșa yol açtığı ve bu sektörlerin birçoğunda üretimi azaltması beklenmektedir.

Koutsouvelis ve Papastathopoulos (2013) çalıșmalarında, Yunanistan'da dolaylı vergiler ile enflasyon arasındaki ilișkiyi doğrusal regresyon modeliyle 2010 ve 2011 yılları için analiz etmișlerdir. Çalıșmaya göre; harmonize edilmiș fiyat indeksi, dolaylı vergilerin enflasyona katkısı 2010 yılı için \%4, 19, 2011 yılında ise \%2,29 olduğunu göstermektedir.

Güvenek vd. (2010) çalıșmalarında Türkiye'de 1980-2008 yılları arasından enflasyon ve dolaylı vergiler arasındaki ilișkiyi VAR analizi ile incelemișlerdir. Çalıșmada elde edilen bulgulara göre, enflasyonda meydana gelen gelișmelerin dolaylı vergi gelirlerinde ve yine aynı șekilde dolaylı vergilerde meydana gelen bir değișmenin ise enflasyona neden olduğu tespit edilmiștir.

Ibadin ve Oladipupo (2015) çalıșmalarında Nijerya'da ekonomik büyüme üzerinde dolaylı vergilerin etkisini 1981-2014 yılları arasında zaman serisi analizi yöntemi kullanarak incelemișlerdir. Elde edilen bul- 
gulara göre, dolaylı vergiler ile gayri safi yurtiçi hasıla arasında pozitif bir ilișki olduğu tespit edilmiștir.

Moździerz (2017) çalıșmasında 2007-2016 yılları arasında Romanya, Macaristan, Yunanistan ve Baltık ülkelerinde (Estonya, Letonya, Litvanya) yaptığı analizde enflasyon ve dolaylı vergiler arasındaki ilișkinin iki yönlü olduğunu tespit etmiștir. Fiyatlar genel seviyesindeki değișikliklerin, vergi matrahını değiștirerek vergi gelirlerini etkilerken, dolaylı vergilerin fiyatları șekillendirmesi nedeniyle enflasyona sebep olduğunu ve bu nedenle enflasyonla mücadele için dolaylı vergilerin oranlarının düșürülmesi gerektiğini ileri sürmüștür.

Çakmaklı vd. (2018) çalıșmalarında Temmuz-2005 ve Temmuz-2017 döneminde Türkiye' de tütün ürünlerine uygulanan dolaylı vergilerin enflasyona etkilerini incelemișlerdir. çalıșma sonuçlarına göre, tütün mamullerine uygulanan dolaylı vergilerin enflasyon üzerinde kısa vadeli bir etkiye sahip olduğu, vergilerde yapılacak 25 baz puan artıșın enflasyon üzerinde 16 baz puanlık bir artıșa neden olacağı tespit edilmiștir.

\section{Veri Yöntem}

Çalıșmanın veri seti, 5018 sayılı Kamu Mali Yönetimi ve Kontrol Kanunu (KMYKK) bütün maddeleri ile yürürlüğe girdiği tarihten sonra hazırlanan merkezi yönetim bütçesi vergi gelirleri dikkate alınarak 2006:M1-2018:M5 dönemi seçilmiștir. Çalıșmada bağımlı değișken olarak tüketici fiyat endeksi değișim oranı (enf), bağımsız değișken olarak dolaylı vergilerin toplam vergi gelirlerine oranı (dv) kullanılmıștır. Değișkenlere ait serilerin mevsim ve takvim etkisinden arındırılmıș hali kullanılmıș olup, durağanlaștırmak amacıyla logaritmaları alınmıștır. Tüketici fiyat endeksi değișim oranları Türkiye İstatistik Kurumu'nun (TÜiK) internet sayfasından, dolaylı vergi gelirlerinin toplam vergi gelirlerine oranı ise Türkiye Cumhuriyet Merkez Bankası Elektronik Veri Dağıtım Sistemi'nden elde edilerek düzenlenmiștir.

\section{- Birim Kök Testi}

Augmented Dickey-Fuller (ADF) testi ve Phillips-Peron (PP) testi kullanılarak serilerin durağanlıkları analiz edilmiștir. Tablo 1'de yer alan ADF birim kök testi sonuçlarına göre " $d v^{\prime \prime}$ değișkeni sabitli-trendli modelde \%5 anlamlılık düzeyinde durağan olduğu, sabitli modelde ise \%5 anlamlılık düzeyinde durağan olduğu tespit edilmiștir. "enf" değișkeninin ise sabitli-trendli modelde ve sabitli modelde $\% 5$ anlamlılık düzeyinde 
durağan olmadığı tespit edilmiștir. "enf" değișkeninin birinci farkı alındığında ise, \%5 anlamlılık düzeyinde durağan olduğu tespit edilmiștir. PP birim kök testi sonuçlarına göre göre " $d v "$ " değișkeni sabitli-trendli modelde ve sabitli modelde \%5 anlamlılık düzeyinde durağan olduğu, "enf" değișkeninin ise sabitli-trendli modelde ve sabitli modelde \%5 anlamlılık düzeyinde durağan olmadığı tespit edilmiștir. "enf" değișkeninin birinci farkı alındığında ise, \%5 anlamlılık düzeyinde durağan olduğu tespit edilmiștir.

Tablo 1. Birim Kök Testi Sonuçları

\begin{tabular}{|c|c|c|c|c|c|}
\hline \multirow{2}{*}{ Değișken } & \multicolumn{2}{c|}{ ADF } & \multicolumn{2}{c|}{ PP } \\
\cline { 2 - 6 } & Sabitli-Trendli & Sabitli & Sabitli-Trendli & Sabitli \\
\hline \multicolumn{2}{|c|}{ enf } & -1.2801 & -1.2499 & -3.2518 & -3.2380 \\
\hline \multicolumn{2}{|c|}{$\Delta$ enf } & $-8.2826^{*}$ & $-8.0984^{*}$ & $-11.4866^{*}$ & $-10.7320^{*}$ \\
\hline \multicolumn{2}{|c|}{$\mathbf{d v}$} & $-5.7907^{*}$ & $-3.1672^{*}$ & $-12.9693^{*}$ & $-12.7387^{*}$ \\
\hline \multicolumn{2}{|c|}{$\Delta \mathbf{d v} \mathbf{v}$} & $-7.5654^{*}$ & $-7.6285^{*}$ & $-54.8064^{*}$ & $-54.4501^{*}$ \\
\hline \multirow{2}{*}{ Kritik Değerler } & $\% 1$ & -4.0269 & -3.4789 & -4.0212 & -3.4748 \\
& $\% 5$ & -3.4432 & -2.8827 & -3.4404 & -2.8809 \\
& $\% 10$ & -3.1463 & -2.5781 & -3.1447 & -2.5772 \\
\hline \hline
\end{tabular}

Not: * ișareti \%1, ** ișareti \%5 düzeyinde değișkenin durağan olduğunu ifade etmektedir. " $\Delta$ " ișareti ise, fark alma operatörünü, yani birinci fark değerlerini ifade etmektedir.

Birim kök testi sonuçlarından elde edilen sonuçlara göre " $d v "$ değișkenin I(0), "enf" değișkenin I(1) düzeyinde durağan olduğu tespit edilmiștir. Değișkenler arasındaki uzun dönem ilișkiyi incelemek için çalıșmaya Otoregresif Dağııılmıș Gecikme Modeli (ARDL) ile devam edilecektir.

\section{- Sinır Testi (Bounds Test)}

ARDL testinin uygulanmasında en önemli așama uygun gecikme uzunluğunun belirlenmesidir. Bu amaçla aylık veri kullanılması nedeniyle 12 gecikmeye kadar modeller tahmin edilmiș ve hesaplanan bilgi kriterleri ve otokorelasyonun varlığı incelenmiștir. Tablo 2 'de yer alan sonuçlara göre $A I C, S C$ ve $H Q$ kriterlerine göre gecikme uzunluğunun minimum olduğu ve otokorelasyonun bulunmadığı 2. gecikme uzunluğu en uygun gecikme uzunluğu olarak belirlenmiștir. 
Tablo 2. Gecikme Uzunluğunun Tespiti

\begin{tabular}{|c|c|c|c|c|}
\hline $\begin{array}{c}\text { Gecikme } \\
\text { Sayıs }\end{array}$ & AIC & SC & HQ & LM (Prob) \\
\hline $\mathbf{1}$ & -1.568508 & -1.487502 & -1.535595 & 0.0011 \\
\hline $\mathbf{2}$ & -1.609591 & -1.487532 & -1.559997 & $\mathbf{0 . 6 1 4 5}$ \\
\hline $\mathbf{3}$ & -1.584359 & -1.420874 & -1.517931 & 0.8203 \\
\hline $\mathbf{4}$ & -1.552493 & -1.347201 & -1.469076 & 0.0071 \\
\hline $\mathbf{5}$ & -1.553200 & -1.305715 & -1.452636 & 0.5028 \\
\hline $\mathbf{6}$ & -1.567357 & -1.277288 & -1.449487 & 0.1931 \\
\hline $\mathbf{7}$ & -1.578684 & -1.245633 & -1.443346 & 0.0796 \\
\hline $\mathbf{8}$ & -1.552647 & -1.176209 & -1.399675 & 0.0449 \\
\hline $\mathbf{9}$ & -1.550023 & -1.129788 & -1.379252 & 0.0316 \\
\hline $\mathbf{1 0}$ & -1.519837 & -1.055388 & -1.331097 & 0.0062 \\
\hline $\mathbf{1 1}$ & -1.492316 & -0.983229 & -1.285436 & 0.0008 \\
\hline $\mathbf{1 2}$ & -1.460533 & -0.906376 & -1.235337 & 0.0057 \\
\hline
\end{tabular}

Uygun gecikme uzunluğunun belirlenmesinin ardından uzun dönem eșbütünleșme ilișkisi incelenmektedir. Uzun dönem eșbütünleșme ilișkisinin belirlenebilmesi amacıyla, sınır testi ile $F$ istatistiği hesaplanmaktadır. Bulunan F istatistiği Peseran'ın kritik değerleriyle karșılaștırılarak uzun dönem ilișkinin varlığı hakkında karar verilmektedir.

Tablo 3. Sınır Testi Sonuçları

\begin{tabular}{|c|c|c|}
\hline Bağımlı Değișken: & \multicolumn{2}{|c|}{ "enf" } \\
\hline Bağımsız Değișken: & \multicolumn{2}{|c|}{ "dv" } \\
\hline F istatistiği: & \multicolumn{2}{|c|}{4.26} \\
\hline Kritik Değerler (k=1) & \multicolumn{2}{|c|}{} \\
\hline & Alt Değer & Üst Değer \\
\hline$\% 5$ & 3.62 & 4.16 \\
\hline
\end{tabular}

Hesaplanan F istatistiğinin \%5 anlamlılık düzeyinde Peseran'ın üsł kritik değerinden büyük olması dolayısıyla "enf" ve "dv" değișkenleri arasında uzun dönem ilișkisi olduğu sonucuna ulașılmıștır. Değișkenler arasında eșbütünleșme ilișkisi tespit edildiğinden uzun ve kısa dönem ilișkileri belirleyebilmek için bu așamada ARDL modeli kurulmaktadır.

\section{- ARDL Model}

Değișkenler arasındaki uzun dönem ilișkisinin incelenmesi için ARDL modeli kurularak uzun dönem ve kısa dönem ilișkileri belirlenmektedir. Uzun dönemli ilișkiyi araștırmak üzere kullanılacak model ARDL $(7,0)$ eșitliğidir. Modelde sadece uzun dönem katsayılarına yer veril- 
mekte ve katsayıların anlamlılığı incelenmektedir. Modelden elde edilen sonuçlar tablo 4 'te sunulmaktadır.

Tablo 4. ARDL $(7,0)$ Modeli Uzun Dönem Katsayıları

\begin{tabular}{|c|c|c|c|}
\hline Değișkenler & Katsayı & t-istatistiği & Prob \\
\hline$d v$ & 0.1011 & 0.2733 & 0.7850 \\
\hline$c$ & 2.1795 & 9.0125 & 0.0000 \\
\hline
\end{tabular}

ARDL uzun dönem sonuçları incelendiğinde, uzun dönemde " $d v "$ değișkeninde yapılacak \% 1'lik artıș "enf" üzerinde \% 0,1'lik bir artıșa neden olmaktadır, ancak bu sonuç istatistiki olarak anlamlı değildir.

Uzun dönemli ilișkinin ortaya konulmasının ardından ARDL $(7,0)$ modeline dayalı hata düzeltme modeli (hdt) kurularak kısa dönemli ilișkiler incelenir. Hata düzeltme modeli sonuçları tablo 5 'te sunulmuștur.

Tablo 5. ARDL $(7,0)$ Modeline Dayalı Hata Düzeltme Modeli

\begin{tabular}{|c|c|c|c|}
\hline Değișkenler & Katsayı & t-istatistiği & Prob \\
\hline$d(e n f(-1))$ & 0.2969 & 3.5239 & 0.0006 \\
\hline$d l e n f(-2))$ & 0.1462 & 1.6608 & 0.0991 \\
\hline$d(e n f(-3))$ & 0.0597 & 0.7173 & 0.4744 \\
\hline$d(\operatorname{enf}(-4))$ & -0.1571 & -1.9019 & 0.0593 \\
\hline$d(\operatorname{enf}(-5))$ & 0.2109 & 2.5066 & 0.0134 \\
\hline$d(\operatorname{enf}(-6))$ & 0.1651 & 1.9132 & 0.0579 \\
\hline$d v$ & 0.0167 & 0.3402 & 0.7342 \\
\hline hdt(-1) & $-\mathbf{0 . 1 9 7 1}$ & -4.0783 & $\mathbf{0 . 0 0 0 1}$ \\
\hline
\end{tabular}

Hata düzeltme modeli sonuçlarına göre kısa dönem hata terimi katsayısının (-0.1971), -1 ile 0 arasında olması ve istatistiki olarak anlamlı olması (Prob:0.0001) hata düzeltme modelinin çalıștığını göstermektedir. Bu parametre, değișkenleri uzun dönem denge değerine yakınlașmaya zorlamaktadır. Hata terimi parametresinin anlamlı olması dolayısıyla değișkenler arasında bir nedensellik söz konusudur.

\section{- Ampirik Bulguların Değerlendirilmesi}

Dolaylı vergiler ile enflasyon arasındaki ilișkinin incelendiği ARDL modeli sonuçlarına göre, hesaplanan F-istatistiğinin Peseran'ın kritik üst değerinden büyük olması ile değișkenler arasında uzun dönem ilișkinin varlığı tespit edilmiștir. Uzun dönem katsayıları incelendiğinde, dolaylı vergilerde meydana gelecek \% l'lik artıșın uzun dönemde enflasyon üzerinde \% 0.1 'lik artıșa neden olacağı belirlenmiș ancak bu durum istatistiki olarak \%5 anlamlılık düzeyinde anlamlı olmadığı tespit edilmiștir. 
Uzun dönem ilișkinin belirlenmesinden sonra kurulan hata düzeltme modeli ile kısa dönem katsayılar ortaya konulmuștur. Hata düzeltme modeli sonuçlarında elde edilen hata düzeltme teriminin 0 ile -1 arasında yer alması ve istatistiki olarak \%5 anlamlılık düzeyinde anlamlı olması kurulan modelin geçerliliği göstermekte olup, hata düzeltme terimi katsayısı ise uzun dönem dengesinden meydana gelecek sapmaların \%19'unun her çeyrek dönem düzeltildiğini göstermektedir.

\section{Sonuç}

Ekonometrik analiz sonuçlarından da elde edilen bulgular neticesinde, dolaylı vergiler ile enflasyon arasında uzun dönemli bir ilișki tespit edilmiștir. Hata düzeltme modelinin de istatistiki olarak anlamlı olması ve katsayının beklenen aralık içerisinde olması, dolaylı vergiler ile enflasyon arasındaki uzun dönemli ilișkinin varlığını doğrulamaktadır. Enflasyonist dönemde uygulanacak maliye politikasının temel hede$\mathrm{fi}$, toplam talebin toplam arzdan fazla olması nedeniyle, toplam talebi daraltıcı maliye araçlarını ön plana çıkararak arz-talep eșitliğini sağlamaya çalıșmaktır. Toplam talebi daraltmak amacıyla maliye politikası aracı olarak harcamalar ve tüketim üzerinden alınan dolaylı vergiler enflasyonla mücadelede etkin bir rol oynamaktadır. Dolaylı vergiler çoğunlukla fiyat mekanizması içine dahil edilip tahsil edildiği için dolaylı vergilerin arttırılması kullanılabilir geliri doğrudan ve hızlı bir șekilde azaltmakta ve kullanılabilir gelirin azalmasına bağlı olarak toplam talepte daralma meydana gelmektedir.

Dolaylı vergiler enflasyonla mücadelede etkin bir rol oynarken, mükelleflerin kișisel özelliklerini dikkate almaması, indirim, istisna ve artan oranlılık söz konusu olmaması nedeniyle gelirinin büyük kısmını harcayan düșük gelirli kișiler üzerinde ağır bir vergi yükü olușturmaktadır. Dolaylı vergilerin mükelleflerin gelirlerini dikkate almaması ve düz oranlı vergiler olması nedeniyle gelir dağılımı üzerinde olumsuz etkiler yaratabilmektedir. Dolaylı vergiler ile enflasyonla mücadele edilirken, toplumun sosyo-ekonomik yapısını bozmayacak düzenlemeleri göz önünde bulundurması da bir politika önerisi olarak sunulmaktadır. 


\section{KAYNAKCุA}

Cural, M.\&Çevik, N. K. (2015), Ekonomik Kalkınmanın Vergi Yapısı Üzerindeki Etkisi: 1924-2013 Dönemi Türkiye Örneği, Amme İdaresi Dergisi, 48(3), 127-158.

Çakmaklı, C., Demiralp, S., Yeșiltaș, S.\&Yıldırım, M. A., (2018), Tütün Ürünlerine Uygulanan Dolaylı Vergilerin Enflasyona Etkileri, Koç University-Tüsiad Economic Research Forum Working Paper Series, No:1811, https://eaf.ku.edu.tr/sites/eaf. ku.edu.tr/files/erf_wp_1811_tr.pdf, (Erișim: 20.06.2018)

Çelik, S.B. (2016), Vergilemede Adalet Açısından Türkiye'nin Dolaysız ve Dolaylı Vergileme Politikası, International Conference on Eurasian Economies, Kaposvár - Hungary 29-31 August, Editors: Selahattin Sarı, Alp H. Gencer, ilyas Sözen, Beykent University Publications No: 115 , İstanbul.

Dickey, D.A.\& Fuller, A.W. (1981), Likelihood Ratio Statistics for Autoregressive Time Series with a Unit Root, Econometrica, 49(4)., 1057-1072.

Erginay, A., (1976), Kamu Maliyesi, Sevinç Marbaası, Ankara.

Garg, G.,(2014), Basic Concepts and Features of Good and Service Tax In India, International Journal of Scientific Research and Management (IJSRM), 2(2), 542-549.

Güvenek, B., Alptekin, V.\&Çetinkaya, M., (2010), Enflasyon ve Dolaylı Vergilerden Elde Edilen Gelirler Arasındaki İlișkinin VAR Yöntemiyle Analizi, Kamu-lș Dergisi, $11(3), 1-28$.

Ibadin, P.O.\&Oladipupo, A.O., (2015), Indirect Taxes And Economic Growth In Nigeria, EKON. MISAO I PRAKSA DBK, GOD XXIV, BR. 2, 345-364

Karadağ, M.\&Westaway, T., (1999), The Impact on Consumer and Producer Prices of Changes in VAT in Turkey Designed to Meet EU Membership Criteria, Economic Research Paper, No. 99/19, Loughborough University, UK,

Koutsouvelis, P.\&Papastathopoulos, A., (2013), The Effects of Indirect Taxes on Consumer Prices: Empirical Evidence for Greece, Advances in Management \& Applied Economics, 3(1), 61-76

Mutlu, A., (2009), Tanzimattan Günümüze Türkiye'de Vergileme Zihniyetinin Gelișimi, Maliye Bakanlığı Strateji Geliștirme Bașkanlığı Yayın No:2009/390, Ankara.

Mutlu, A.\&Çelen, M., (2012), Dolaylı ve Dolaysız Vergilerin Türk Mali Sistemi İçerisindeki Yeri: Siyasal, Sosyal ve Ekonomik Sonuçları, TÜSIAD Yayınları, İstanbul

Özçelik, Ö., (2015), Türk İktisat Tarihi, Academia Yayınevi, Kütahya.

Pesaran, M.H., Shin, Y.\& Smith, R.J. (2001), Bounds Testing Approaches to the Analysis of Level Relationships, Journal of Applied Econometrics, 16, 289-326.

Phillips, P.C. B ve Perron, P. (1988), Testing for a Unit Root in Time Series Regression, Biometrika, 75(2), 335346

Șen, H. ve Sağbaș, I.,(2015), Vergi Teorisi ve Politikası, Kalkan Offset, Ankara. 
Șen, H., (2003), Olivera-Tanzi Etkisi: Türkiye Üzerine Ampirik Bir Çalıșma, Maliye Dergisi, Sayı: 143, 30-57

TCMB (2013), Enflasyon ve Fiyat İstikrarı, Türkiye Cumhuriyet Merkez Bankası İdare Merkezi, Ankara.

Totonchi, J., (2011), Macroeconomic Theories of Inflation, 2011 International Conference on Economics and Finance Research, IPEDR Vol.4, IACSIT Press, Singapore, $459-462$. 